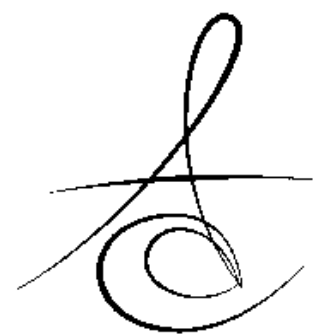

Makale Kodu/Article code: 1467

Makale Gönderilme tarihi: 21.01.2014

Kabul Tarihi: 08.04.2014

\section{SERAMİK İNLEY RESTORASYONLAR}

\section{CERAMIC INLAY RESTORATIONS}

\author{
Dr. Özgür ÖZTÜRK*
}

\section{ÖZET}

Dental seramiklerin fiziksel özelliklerinin ve seramik-rezin siman bağlantısının geliştirilmesi ile seramik restorasyonların posterior bölgede kullanımı yaygınlaşmıştır. Seramik inleyler adeziv teknikle beraber kullanıldığında minimal preparasyonla kalan diş yapısını koruyan estetik bir tedavi alternatifi sunarlar. Bu derlemenin amacı seramik inleylerin endikasyon ve kontrendikasyonları, avantaj ve dezavantajları, restorasyonun başarısını etkileyen faktörler hakkında genel bilgi vermektir.

Anahtar kelimeler: Dental İnlayler, Dental Porselen, Diş Protezi

\section{SERAMİK İNLEY RESTORASYONLAR}

İnley restorasyonlar, diş çürüğü nedeni ile oluşan Class I ve II madde kayıplarının tedavisinde yaygın olarak kullanılan intrakoronal restorasyonlardır ${ }^{1}$. İnley restorasyonlar metal, kompozit veya seramikten yapılabilmektedir ${ }^{1}$. Günümüzde hastaların sıklıkla diş renginde materyalleri tercih etmeleri nedeni ile daha çok kompozit ve seramik kullanılmaktadır.

Posterior direkt kompozit restorasyonlar; estetik olmaları, tek seansta bitirilmeleri ve kalan diş dokusunu koruma avantajlarına sahipken, yeterli proksimal kontakt ve oklüzal morfolojiyi sağlamanın zor olması dezavantajlarıdır ${ }^{2,3}$.

Kompozit rezinler, polimerizasyonları sırasında uzunluklarında \%0.2-1.9, hacimlerinde \%1-4 oranında azalma gösterirler. Bu büzülme kompozit rezini bağlı olduğu diş yapısından ayıracak kuvvetler

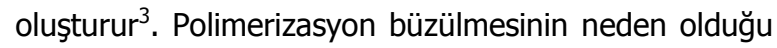
bu kontraksiyon kuvvetleri, diş ve kompozit arasındaki bağlantıyı bozarak marjinal açıklığa, mikrosızıntıya, pulpal irritasyona, postoperatif hassasiyete ve

\section{ABSTRACT}

The use of ceramic restorations in the posterior region has become widespread due to the development of physical properties of dental ceramics and ceramic-resin cement bonding. Ceramic inlays when used with adhesive technique protect the remaining tooth structure and offer an aesthetics alternative treatment. The aim of this review was to provide general information about indications, contraindications, advantages, disadvantages and factors of affecting the success of the ceramic inlays.

Key words: Dental Inlays, Dental Porcelain, Dental Prosthesis.

Bu problemlerin üstesinden gelmek için indirekt kompozit restorasyonlar geliştirilmiştir. Bu yöntemle hem anatomik form ve proksimal kontaktların oluşturulması kolaylaştırılmış hem de polimerizasyon büzülmesi sadece ince rezin siman tabakası ile sınırlandırılmıştır ${ }^{2,3}$.

Direkt ve indirekt yöntem ile hazırlanan posterior kompozit restorasyonlarda mikrosızıntının incelendiği bir çalışmada indirekt yöntemin mikrosızıntıyı anlamlı olarak azalttığı belirtilmiştir ${ }^{4}$.

İlk geliştirilen dental seramiklerin düşük kırıma dirençleri nedeni ile posterior bölgede kullanımları kısıtlı kalmıştır. Zamanla yüksek dirençli seramiklerin ve porselen yüzeyinin asitlenerek rezin simanlar ile diş yüzeyine adeziv bağlantının geliştirilmesi ile seramik restorasyonların posterior bölgede kullanımı yaygınlaşmıştır ${ }^{5-8}$.

Seramik inleyler Class I veya II restorasyonlar için estetik bir alternatif sunarlar. Seramik inleyler yüksek estetiğe, renk stabilitesine ve dirence sahiptirler $^{2,3}$. Ancak yapımlarının zaman alıcı olması, ilave bir seans ve teknik hassasiyet gerektirmeleri ve direkt

* Gülhane Askeri Tıp Akademisi Diș Hekimliăi Bilimleri Merkezi Protetik Diş Ted. A.D 
kompozit restorasyonlara göre pahalı olmaları dezavantajlarıdır ${ }^{2,3,5,9}$.

\section{Seramik İnleylerin Endikasyon ve Kontrendikasyonları}

Seramik inleyler sıklıkla molar dişlerin fissürlerinden başlayan santral kavitelerin restorasyonlarında kullanılır. Seramik inleyler, bukkal ve lingual duvarların sağlam olduğu Class II restorasyon gereken kavitelerde ve direkt posterior kompozit restorasyon yapılamayan durumlarda amalgam veya döküm metal restorasyonlara geçerli bir tedavi alternatifi sunmaktadır ${ }^{5,10}$.

Düşük plak kontrolü ve çürük aktivitesi yüksek olan hastalarda seramik inley yapımı uygun değildir. Seramik inley restorasyonların başarısızlığında primer sebep seramik kırı̆ı̆ı olduğundan aşırı oklüzal kuvvetlerden kaçınılmalıır. Bu nedenle klinik kuron boyu kısa dişlerde, interoklüzal aralı̆ın yetersiz olduğu durumlarda, uygun olmayan oklüzyon varlığında ve parafonksiyonel alışkanlığı olan hastalarda tedbirli olunmalıdır $^{5,11}$.

Seramik inley restorasyonun başarısında simantasyon önemli bir aşama olduğundan izolasyon sağlamanın zor olduğu derin servikal subgingival marjinal yerleşimde tercih edilmemelidir ${ }^{5,12}$.

\section{Seramik İnleylerin Avantaj ve \\ Dezavantajları}

Dişin doğal morfolojisini restore etmesi, aşınmaya dirençli olması, biyouyumlu olması, polimerizasyon büzülmesinin siman film tabakası ile sınırı kalması, uzun ömürlü ve estetik olması seramik inleylerin avantajlarıdır ${ }^{6,13}$.

Seramiğin termal ekspansiyon katsayısı dişe benzer olduğundan hacimsel büzülme kompozit restorasyonlara göre daha az olmaktadır. Bu özellik seramik inleylerin marjinal uyumunun daha iyi olmasını sağlamaktadır ${ }^{14}$.

Seramikte kırık olması restorasyonun dezavantajı olarak görülse de uygun materyal seçimi, kaliteli adeziv bağlanma ve uygun form ve boyutlarda kavite preparasyonu ile restorasyonun ömrü uzatılabilir ${ }^{13}$.

\section{Faktörler}

Seramik İnleylerin Başarısını Etkileyen

\section{Preparasyon}

Seramik inleylerde restorasyonun uyumu, direnci ve estetiği için diş preparasyonunun dizaynı önemlidir. Posterior dişlerde adeziv tekniklerle beraber seramik kullanımı, kalan diş yapısının korunması ve daha estetik restorasyonlar yapılmasını sağlar ${ }^{15}$.

Diş preparasyonu, dişin yapısal direncinin $\% 50$ 'ye yakın oranda azalmasına neden olur ki bu da dişin kırıma riskini arttırmaktadır ${ }^{6}$. Bu nedenle seramik inley preparasyonunda kabul gören genel görüş minimal preparasyon yapılmasıdır. Genel olarak minimum 1.5-2 mm pulpal taban derinliği, 1-1.5 mm aksiyal redüksiyon ve $2 \mathrm{~mm}$ istmus genişliği yeterli preparasyon boyutlarıdır. Oklüzal kuvvetler karşısında kırıma direncini arttırmak için istmus genişliği minimize edilmelidir ${ }^{5}$. Yetersiz materyal kalınlığı restorasyonda kırı̆ga neden olacaktır. Bu nedenle uygun materyal kalınlığına izin veren preparasyon boyutları sağlanmalıdır ${ }^{5}$.

Yapılan bir çalışmada MOD kavite hazırlanmış premolar dişin kırılma direnci sağlam premolar dişin kırıma direnci ile karşılaştııımış̧ı. Çalışma sonucunda MOD kavite preparasyonunun dişin kırılma direncini $\% 33,7$ oranında azalttığı belirtilmiştir ${ }^{16}$.

Dejak ve ark. ${ }^{17}$ farklı preparasyon dizaynlarına sahip seramik inley restorasyonlarda stres dağılımını sonlu eleman analizi yöntemi ile inceledikleri çalışmalarında bevel yapılan marjinlerde yer alan ince, keskin kenarlı seramiklerde çiğneme sırasında kırılmaya neden olabilecek stres dağıımı gözlendiğini, butt-joint marjinlerin stres dağılımı açısından daha uygun olduğunu belirtmişlerdir. Ayrıca çalışmada $5 \mathrm{~mm}$ istmus genişliğine sahip seramik inleylerde $3 \mathrm{~mm}$ istmus genişliğine göre uygun olmayan stres dağılımının daha fazla olduğu belirtilmiştir. Bu nedenle yazarlar molar dişlerde geniş preparasyonlarda inley restorasyonlar yerine onley restorasyonları önermişlerdir.

Preparasyonun derinliği seramik inley restorasyonlarda sadece dişin direncini etkilemekle kalmaz aynı zamanda restorasyonun altında kalan dentin dokusu arttıkça restorasyonun dişe bağlanma kuvveti de artmaktadır $^{18}$.

\section{Marjinal ve İnternal Uyum}

Marjinal ve internal uyum seramik inley restorasyonların klinik performansında önemli bir rol oynamaktadır. Çeşitli çalışmalarda oklüzal bölgede internal açıklık $100 \mu m$ 'den fazla olduğunda rezin simanda aşınmanın daha fazla olduğu, bu açıkıı̆ın proksimal yüzeyde dişetine yakın bölgede olduğunda gingival enflamasyon ve periodontal hastalık riskini arttırdığı göste- 
rilmiştir $^{19-22}$. Marjinal açıklık fazla olduğunda rezin siman ağız ortamı ile temasa geçmekte böylece restorasyonla diş arasındaki bağlantı bozulmaktadır. Sonuçta oluşan mikrosızıntı nedeni ile potansiyel irritanlar pulpal hasara neden olmaktadır 2,19-22.

Özyeşil ve Kesim ${ }^{23}$ yaptıkları çalışmada inley restorasyonlarda yapay yaşlandırma sonrası marjinal adaptasyon bozukluğunun en çok oklüzal bölgede gözlendiği sonucuna varmışlardır. Yazarlar bunun oklü- zal kuvvetler ve fırçalama testlerinin oklüzal bölgeden yapılmasının neticesi olabileceğini belirtmişlerdir.

Zarrati ve ark. $^{2}$ MOD kavitenin restorasyonunda direkt kompozit restorasyon, indirekt kompozit restorasyon ve seramik inley kullanarak marjinal, oklüzal ve proksimal açıklığı değerlendirmişlerdir. Çalışma sonucunda her 3 restorasyonda da klinik olarak kabul edilebilir $(<100 \mu \mathrm{m})$ marjinal açıklık değeri elde edilmiştir.

\section{Mikrosızıntı}

Kavite duvarları ve restoratif materyal arasında yeterli adezyonun sağlanması restorasyonun ömrü açısından önemlidir. Restorasyonlu dişlerde görülen sekonder çürük, pulpal enflamasyon ve pulpa nekrozunun en önemli sebebi kavite duvarları boyunca karyojenik bakterilerin sızmasıdır. Mikrosızıntının muhtemel belirtileri postoperatif hassasiyet, kronik hassasiyet ve marjinal renklenmedir. Restorasyon kenarları minede yer aldığında; mikrosızıntı minimalize edilmiş olsa da dentin arayüzünde mikrosızıntı problemi henüz tam olarak aşılamamıştı ${ }^{19,24-27}$.

Seramiğin termal genleşme katsayısının diş sert dokularının termal genleşme katsayısı ile benzer olması ve polimerizasyon büzülmesinin sadece rezin siman tabakası ile sınırlı kalması seramik inleylerin marjinal adaptasyonu üzerine olumlu bir etkiye sahiptir ${ }^{25}$.

Kitayama ve ark. ${ }^{28}$ yapmış oldukları çalışmada CEREC inleylerde adeziv simantasyonla beraber kavitenin dentin bonding ajan ve akışkan kompozit ile kaplanmasının diş-rezin arayüzünde mikrosızıntıyı anlamlı oranda azalttığını belirtmişlerdir.

Çürük dentinin kavite tabanı ve duvarlarından uzaklaştırılmasından sonra smear tabakası ve dentin tübülleri içerisinde kalan mikroorganizmaların ortadan kaldırılması sekonder çürüklerin ve postoperatif hassasiyetin azaltılması açısından önemlidir. Bu amaçla kavite dezenfektanlarının kullanımı önerilmektedir. Karaarslan ve ark. ${ }^{29}$ PAD (Photo-activated disinfec- tants) yöntemi ile kavite dezenfeksiyonunun seramik inley restorasyonlarda mikrosızıntıyı önemli oranda azalttığını belirtmişlerdir.

\section{Simantasyon}

Seramik inley restorasyonların başarısı büyük oranda diş yüzeyi ile güvenilir bir bağlantıya bağlıdır. Bu amaçla seramik inley restorasyonların simantasyonunda dual polimerize veya ışıkla polimerize rezin simanlar kullanılır. Rezin siman kullanımı konvansiyonel simanlara göre; tüm yüzeylerde güçlü bir bağlantı sağlaması, renk uyumu, marjinal alanlarda polisajlanabilmesi ve gelişmiş fleksural özellikler gibi avantajlara sahiptirler ${ }^{14}$.

Geleneksel çinko fosfat veya cam iyonomer siman gibi asit bazlı simanlarla simante edilen seramik inleylerin kırılma direncinin adeziv simantasyon yapılan inleylere göre düşük olduğu gösterilmiştir ${ }^{6,30}$.

Siman seçimi restorasyonun yapıldığı materyale göre belirlenmelidir. Seramik inley feldspatik porselen, lityum disilikat veya lösitle güçlendirilmiş seramikler gibi silika bazlı seramikten üretilmişse; bu seramikler hidroflorik asitle pürüzlendirilebildiğinden rezin siman ile simante edilmeleri uygun olacaktır. Bununla beraber lityum disilikat cam seramikler internal yüzey işlemi uygulanmadan klasik simanlarla da simante edilebilmektedir ${ }^{5,31}$.

Yoğun sinterize zirkonyum veya yoğun sinterize alüminyum oksitten üretilen inleyler hem asidik ajanlar tarafından pürüzlendirilemez hem de silika bazlı olmadıkları için silika silan bağlantısı yapamazlar ${ }^{32}$. Bu restorasyonlar çinko fosfat veya cam iyonomer siman gibi klasik simanlarla yapıştırılabilirler ${ }^{5}$. Al, Zr, Ti, Cr gibi metal oksitlerle kimyasal bağlantı kurarak daha yüksek bağlanma direnci sağlayan MDP (10-metakriloksidesil dihidrojen fosfat) gibi fosfat ester monomerleri içeren rezin simanların kullanımı bu restorasyonların simantasyonunda tavsiye edilmektedir ${ }^{33}$.

Adeziv simantasyon işleminin basamaklarını azaltan self-adeziv rezin simanların seramik inleylerin simantasyonunda kullanımı ile ilgili literatürde yer alan klinik bir çalışmada self-adeziv resin siman ve konvansiyonel rezin simanla simante edilen IPS Empress (Ivoclar Vivadent AG Schaan, Liechtenstein) inley restorasyonların klinik özellikleri karşılaştırılmıştır. 2 yıl sonunda self-adeziv rezin siman ile simante edilen restorasyonlarda konvansiyonel rezin siman ile simante edilen restorasyonlar ile benzer klinik sonuçlar 
görüldüğü belirtilmiştir ${ }^{34}$. Peumans ve ark. ${ }^{27}$ yapmış oldukları klinik çalışma sonucunda self-adeziv rezin siman öncesi diş yüzeyinin asitlenmesinin seramik inley restorasyonun ömrü ve marjinal bütünlüğü açısından anlamlı bir fark yaratmadığını göstermişlerdir.

\section{Restorasyonun Ömrü}

Seramik inley restorasyonun ömrü; uygun endikasyona, kullanılan materyalin özelliklerine ve kaliteli bir adeziv bağlanma sağlanmasına bağlıdır. Seramik inleyin kırılması restorasyonun kaybına neden olan majör komplikasyondur ${ }^{13,35,36}$.

Seramiğin gerilme streslerine hassas olmasından dolayı restorasyonun kırılma direnci restorasyonun boyutlarına ve materyalin fiziksel özelliklerine bağlıdır. Ancak Holberg ve ark. ${ }^{13}$ yaptıkları çalışmada farklı kalınlıklarda üretilen $(0.7-2 \mathrm{~mm})$ inley restorasyonlar arasında kırılma direnci açısından anlamlı fark olmadığını belirtmişlerdir. Ancak farklı kırılma direncine sahip Emax ve Empress (Ivoclar Vivadent AG Schaan, Liechtenstein) tam seramik materyaller ile yapılan inley restorasyonların kırılma direnci arasında anlamlı farklılık olduğunu belirtmişlerdir.

Banditmahakun ve ark. ${ }^{36}$ yaptıkları çalışmada seramik inleyin altında elastisite modülü yüksek bir kaide maddesi kullanılmasının restorasyonun kırılma direncini arttırdığını göstermişlerdir.

Hitz ve ark. ${ }^{37}$ endodontik tedavili molar dişlerde fiberle güçlendirilmiş kompozit restorasyonun kırılma direncinin kompozit restorasyona göre yüksek olduğunu ancak seramik inleye göre düşük olduğunu bulmuşlardır. Çalışmada fiber uygulamasının kompozit rezin restorasyonun marjinal uyumu üzerinde olumsuz bir etki yarattığı görülmüştür.

Seramik inley restorasyonlarda bir diğer önemli nokta da restore edilmiş dişin çiğneme kuvvetlerine karşı kırılma direncinin yeterli olmasıdır. Bu noktada restore edilmiş dişin yapısal bütünlüğü, materyalin direncinden daha önemlidir ${ }^{19}$. Dişin kırılma direnci mümkün olduğunca adeziv teknikle bağlanmış bir restorasyonla minimal bir kavite preparasyonu yapılarak arttırılabilir ${ }^{19}$. Posterior dişlerde kaspları içermeyen MOD tip kavite preparasyonu; oklüzal minenin kaldırılması, marjinal kenarların bozulması ve kasp hacminin azaltılması ile sonuçlanır. Tüm bunlar, stresin kaspların kaidesinde toplanmasına neden olarak kırık riskini arttırmaktadır. Bu nedenle derin ve geniş kavitelerde zayıflayan tüberkülleri güçlendirme- yeceğinden amalgam veya metal inley gibi non adeziv restorasyonların yapımı uygun değildir ${ }^{6}$.

Soares ve ark. ${ }^{16}$ yapmış oldukları çalışmada çeşitli restoratif materyaller ile restore edilen endodontik tedavili premolar dişlerin kırılma direncini karşılaştırmışlardır. Çalışma sonucunda yazarlar en düşük kırılma direncinin amalgam ile restore edilen dişlerde gözlendiğini belirtmişlerdir. En yüksek kırılma direnci indirekt kompozit ile restore edilen dişlerde elde edilirken indirekt kompoziti sırasıyla direkt kompozit ve seramik inley restorasyonlu dişler izlemiştir. Amalgam ile restore edilen dişlerin düşük kırıma direnci amalgam ve diş arasında adeziv bağlanmanın olmaması ile açıklanmıştır.

Seramik inley ile restore edilen dişin kırıma direncini etkileyen bir diğer faktör de dişin vitalitesidir. Endodontik tedavili dişler geniş ve derin kavite preparasyonu nedeni ile yapısal olarak zayıflamaktadır $^{38}$. Ayrıca endodontik tedavi sonrası dentinin dehidrate olması ve kollajen çapraz bağlarını kaybetmesinin de dişin kırılma direncini olumsuz yönde etkilediği bilinmektedir ${ }^{38}$. Endodontik tedavili dişlerde bir veya daha fazla kaspı içeren onley restorasyonların kullanılan restoratif materyalden bağımsız olarak inley restorasyonlara göre stres dağılımı açısından daha uygun olduğu belirtilmiştir ${ }^{39}$.

Eyüboğlu ve ark. $^{40}$ inley restorasyonlarda oklüzal kuvvetlerin diş dokusu yerine restoratif materyale gelmesinin diş ve restorasyonun bütünlüğü açısından olumlu olacağını belirtmişlerdir. Ona ve ark. ${ }^{41}$ ise çalışmalarında oklüzal temasların restorasyon marjinine yakın yer alması halinde oklüzal yüzeyde kırığa neden olacak adeziv kırık riskini arttırdığını rapor etmişlerdir.

Habekost ve ark. ${ }^{42}$ yapmış oldukları çalışmada seramik inleyin simantasyonunda kullanılan rezin simanın elastisite modülünün yüksek olmasının dişin kırılma direncini arttırdığını belirtmişlerdir.

İki kasplı premolar dişler, molar dişlere göre restorasyon kavitesinin daha küçük olması, çiğneme kuvvetlerinin etkisi, adeziv arayüzde oluşan streslerin daha az olması ve yapım kolaylığı nedeni ile seramik inley yapımı açısından daha uygundur ${ }^{43}$.

Costa ve ark. $^{44}$ premolar dişler üzerinde yaptıkları çalışmada molar dişlerde olduğu gibi istmus genişliğinin dişin kırılma direncini etkileyen bir faktör olduğunu göstermişlerdir. Ayrıca çalışma sonucunda seramik inley ile restore edilen premolar dişlerin 
kırıma direnci kompozit rezinle restore edilen dişlere göre yüksek bulunduğu belirtilmiştir.

Lange ve ark. ${ }^{45}$ seramik inley restorasyonların

klinik özelliklerini kompozit restorasyonlar ile karşılaştırmışlardır. Çalışmada 250 seramik inley ve 135 kompozit restorasyon 57 ayllk periyotta klinik olarak değerlendirilmiştir. Yazarlar, seramik inleylerin ömrü (\%94) ile kompozit restorasyonların ömrü (\%93) arasında istatistiksel olarak anlamlı fark olmadığını belirtmişlerdir. Çalışma sonucunda seramik inley restorasyonlar marjinal adaptasyon, anatomik form, renk uyumu ve marjinal renklenme açısından kompozit restorasyonlara göre daha iyi bulunsa da bu fark istatistiksel olarak anlamlı değildir. Sekonder çürük ve yüzey pürüzlülük değerleri ise benzer bulunmuştur.

\section{SONUÇ}

Günümüzde estetik beklentilerin artması ile posterior dişlerde de diş renginde restorasyonlar tercih edilmektedir. Diş hekimliği pratiğinde sıkıkla kullanılan kompozit restorasyonlar estetik beklentileri karşılamalarına rağmen polimerizasyon büzülmesi ve mikrosızıntı gibi dezavantajlara sahiptirler. Üstün estetik, gelişmiş fiziksel özellikleri ve biyouyumlulukları ile seramik inleyler posterior bölgede estetik bir tedavi seçeneği sunmaktadırlar.

\section{KAYNAKLAR}

1. Fron Chabouis H, Smail Faugeron V, Attal JP. Clinical efficacy of composite versus ceramic inlays and onlays: A systematic review. Dent Mater. 2013 Oct 8. pii: S0109-5641(13)00440-5. doi: 10.1016/j.dental.2013.09.009.

2. Zarrati S, Mahboub F. Marginal adaptation of indirect composite, glass-ceramic inlays and direct composite: an in vitro evaluation. J Dent (Tehran) 2010;7:77-83.

3. Arıkan S. Posterior kompozit restorasyonlar. Cumhuriyet Üniv. Diş Hek. Fak. Derg 2005; 8:6370.

4. Milleding P. Microleakage of indirect composite inlays. An in vitro comparison with the direct technique. Acta Odontol Scand 1992; 50:295-301.

5. Hopp CD, Land MF. Considerations for ceramic inlays in posterior teeth: a review. Clin Cosmet Investig Dent 2013;18:21-32.
6. Cubas GB, Habekost L, Camacho GB, Pereira-Cenci $\mathrm{T}$. Fracture resistance of premolars restored with inlay and onlay ceramic restorations and luted with two different two different agents. J Prosthodont Res 2011;55:53-9.

7. Pol CW, Kalk W. A systematic review of ceramic inlays in posterior teeth: an update. Int J Prosthodont 2011;24:566-75.

8. Başbuğ S, Gözneli R. Tam seramik sistemler: konvansiyonel yöntemler. Atatürk Üniv. Diş Hek. Fak. Derg 2012;6: 147-154.

9. Desai PD, Das UK. Comparison of fracture ressitance of teeth restored with ceramic inlay and resin composite: an in vitro study. Indian J Dent Res 2011;22:877-82.

10. Field C, Li Q, Li W, Thompson M, Swain M. A comparative mechanical and bone remodelling study of all-ceramic posterior inlay and onlay fixed partial dentures. J Dent 2012;40:48-56.

11. Küçükeşmen HC. Porselen İnley-Onleyler. Türkiye Klinikleri J Dental Sci-Specia Topics 2011; 2: 22-8.

12. Zaruba M, Göhring TN, Wegehaupt FJ, Attin T. Influence of a proximal magrin elevation technique onmarginal adaptation of ceramic inlays. Acta Odontol Scand 2013;71:317-24.

13. Holberg C, Winterhalder $P$, Wichelhaus A, Hickel $R$, Huth K. Fracture risk of lithium-disilicate ceramic nlays: A finite element analysis. Dent Mater 2013;29:1244-50.

14. Cekic I, Ergun G, Uctasli S, Lassila LV. In vitro evaluation of pushout bond strength of direct ceramic inlays to tooth surface with fiberreinforced composite at the interface. J Prosthet Dent 2007;97:271-8.

15. Morimoto S, Vieira GF, Agra CM, Sesma N, Gil C. Fracture strength of teeth restored with ceramic inlays and overlays. Braz Dent J 2009;20:143-8.

16. Soares PV, Santos- Filho PC, Martins LRM, Soares $\mathrm{CJ}$. Influence of restorative technique on the biomechanical behaviour of endodontically treated maxillary premolars. Part I: Fracture resistance and fracture mode. J Prosthet Dent 2008; 99:30-7.

17. Dejak B, Mlotkowski A, Romanowicz M. Strength estimation of different designs of ceramic inlays and onlays in molars based on the Tsai-Wu failure criterion. J Prosthet Dent 2007;98:89-100. 
18. Öztürk N, Aykent F. İki farklı seramik inley sisteminin bağlanma dayanımına kalan dentin kalınlığının etkisinin araştırılması. Cumhuriyet Üniv Diş Hek Fak Derg 2001;4:75-79.

19. Keshvad A, Hooshmand T, Asefzadeh F, Khalilinejad $F$, Alihemmati $M$, Van Noort $R$. Marginal gap, internal fit and fracture load of leucite-reinforced ceramic inlays fabricated by CEREC inLab and hot-pressed techniques. J Prosthodont 2011;20:535-40.

20. Schmalz G, Federlin M, Reich E. Effect of dimension of luting space and luting composite on marginal adaptation of a class II ceramic inlay. ] Prosthet Dent 1995;73:392-9.

21. O'Neal SJ, Miracle RL, Leinfelder KF. Evaluating interfacial gaps for esthetic inlays. J Am Dent Assoc 1993; 124:48-54.

22. Sheets CG. The periodontal-restorative interface: enhancement through magnification. Pract Periodontics Aesthet Dent 1999;11:925-31.

23. Özyeşil AG, Kesim B. Estetik inleylerin marjinal adaptasyonunun incelenmesi. Cumhuriyet Üniv Diş Hek Fak Derg 2001;4:110-114.

24. Thordrup $M$, Isidor $F$, Hörsted-Bindslev $P$. Comparison of marginal fit and microleakage of ceramic and composite inlays: an in vitro study. J Dent 1994;22:147-53.

25. Uludağ B, Ozturk O, , Ozturk AN. Microleakage of ceramic inlays with different resin cements and dentin adhesives. J Prosthet Dent 2009;102:23541.

26. Çelik EU, Kumbaracı N, Çal E, Turkun M. Influence of two desensitizer agents on the microleakage of adhesively luted ceramic inlays. Eur J Dent 2011;5:77-83.

27. Peumans M, Voet M, De Munck J, Van Landuyt K, Van Ende A, Van Meerbeek B. Four-year clinical evaluation of a self-adhesive luting agent for ceramic inlays. Clin Oral Investig 2013;17:739-50.

28. Kitayama S, Nasser NA, Pilecki P, Wilson RF, Nikaido T, Tagami J, Watson TF, Foxton RM. Effect of resin coating and occlusal loading on microleakage of Class II computer-aided manufacturing fabricated ceramic restorations:a confocal microscopic study. Acta Odontol Scand 2011;69:182-92.
29. Karaarslan EŞ, Altıntaş S, Cebe MA, Üşümez A. Işıkla aktive edilen dezenfeksiyon (PAD) işlemi uygulanmış seramik inley restorasyonlarda mikrosızıntının değerlendirilmesi. Atatürk Üniv Diş Hek Fak Derg 2011; 21:108-114.

30. Filho AM, Vieira LCC, Araujo E, Baratieri LN. Ceramic inlays and onlays: clinical procedures for predictable results. J Esthet Restor Dent 2003;15:338-351.

31. Michelini FS, Belser UC, Scherrer SS, De Rijk WG. Tensile bond strength of gold and porcelain inlays to extracted teeth using three cements. Int J Prosthodont 1995; 8:324-331.

32. Karakoca S, Yılmaz H. Zirkonyum ve sabit protezlerde kullanımı. Atatürk Üniv. Diş Hek Fak Derg 2006; 36-44.

33. Borges GA, Goes MF, Platt JA, Moore K, Menezes $\mathrm{FH}$, Vedovato $\mathrm{E}$. Extrusion shear strength between an alumina-based ceramic and three different cements. J Prosthet Dent 2007;98: 208-215.

34. Taschner $\quad M$, Krämer $\quad N$, Lohbauer $\quad U$, Pelka $M$, Breschi $L$, Petschelt A, Frankenberger $R$. Leucite-reinforced glass ceramic inlays luted with self-adhesive resin cement: a 2-year in vivo study. Dent Mater 2012;28:535-40.

35. Stoll R, Cappel I, Jablonski-Momeni A, Pieper K, Stachniss V. Survival of inlays and partial crowns made of IPS Empress after a 10-year observation period and in relation to various treatment parameters. Oper Dent 2007;32:556-63.

36. Banditmahakun S, Kuphausuk W, Kanchanavasita W, Kuphasuk C. The effect of base materials with different elastic moduli on the fracture loads of machinable ceramic inlays. Oper Dent 2005;31:180-7.

37. Hitz T, Ozcan M, Göhring TN. Marginal adaptation and fracture resistance of root-canal treated mandibular molars with intracoronal restorations: effect of thermocycling and mechanical loading. J Adhes Dent 2010;12:279-86.

38. Yıkılgan İ, Bala O. Endodontik tedavi görmüş dişlerin konservatif restorasyonları. Acta Odontol Turc 2013;30:44-8.

39. Jiang $W$, Bo $H$, Yongchun G, LongXing N. Stress distribution in molars restored with inlays or onlays with or without endodontic treatment: a threedimensional finite element analysis. J Prosthet Dent 2010;103:6-12. 
40. Eyüboğlu TF, Önal B, Erdilek N, Gören B, ergücü Z. Molar dişlerde inley restorasyonların mekanik performansının incelenmesi: 3-boyutlu sonlu elemanlar analizi. Gazi Üniv Diş Hek Fak Derg 2008;25:27-33.

41. Ona M, Watanabe C, Igarashi $\mathrm{Y}$, Wakabayashi N. Influence of preparation design on failure risks of ceramic inlays: a finite element analysis. J Adhes Dent 2011;13:367-73.

42. Habekost L de V, Camacho GB, Demarco FF, Powers JM. Tensile bond strength and flexural modulus of resin cements-influence on the fracture resistance of teeth restored with ceramic inlays. Oper Dent 2007;32:488-95.

43. Fron Chabouis $\mathrm{H}$, Prot $\mathrm{C}$, Fonteneau C, Nasr K, Chabreron O, Cazier S, Moussally C, Gaucher A, Khabthani Ben Jaballah I, Boyer R, Leforestier JF, Caumont-Prim A, Chemla F, Maman L, Nabet C, Attal JP. Efficiacy of composite versus ceramic inlays and onlays: study protocol for the CECOIA randomized controlled trial. 2012;14:278. doi:10.1186/1745-6215-14-278.

44. Costa A, Xavier T, Noritomi P, Saavedra G, Borges A. The Influence of Elastic Modulus of Inlay Materials on Stress Distribution and Fracture of Premolars. Oper Dent. 2014;39:160-70.

45. Lange RT, Pfeiffer P. Clinical evaluation of ceramic inlays compared to composite restorations. Oper Dent 2009;34:263-72.

\section{Yazışma Adresi:}

Dr. Dt. Özgür ÖZTÜRK

Gülhane Askeri Tıp Akademisi Diş Hekimliği Bilimleri Merkezi Protetik Diş Ted. A.D.

Etlik/ Ankara

Tel : : +903123046052

Fax : +903123046020

E-mail : dtozgur@gmail.com 